\title{
An Assessment of Physical and Physiological Effect of Training Programme on Female Hockey Players
}

\author{
Dr. Sujay Bisht \\ Assistant Professor, L.N.I.P.E, N.E.R.C, Guwahati (Assam), India
}

\begin{abstract}
The purpose of the study was to assess the effect of training on selected physical and physiological variables on women's field hockey players were selected from Madhya Pradesh state women's hockey academy, Gwalior. The study involved 30 female field hockey players and age level ranged from 16 to 21 years. These hockey players had represented various national and international tournaments. Speed, agility, vital capacity \& Vo2 max were selected as a variable. one year long term training programme was adopted and data were collected in different phase of training. The collected data was statistically analyzed by using ANOVA (F-Ratio) and level of significance was 0.05 . The analysis exhibits that speed, agility, Vital capacity \& Vo2max were found significant among the group. The calculated $F$ - ratio for speed (3.32), agility (8.23), vital capacity (27.09) \& Vo2 max (8.08) was significant at 0.05 levels. On the basis of the analysis of data and the limitation of the present study, speed result showed better performance in post preparatory phase (PPP) timing of the subject was decrease accordingly from preparatory to competition phase and with regards to agility it showed positive effect of training in different phase of training. On the other hand physiological variables i.e. vital capacity (27.09) and Vo2 max (8.08) were found significant. It was found vital capacity highly improves mainly after preparatory phase of training. There was significant effect of training on Vo2 max mainly after competition phase and other phase also noticed significant improvement too.
\end{abstract}

Keywords: vital capacity \& Vo2 Max

\section{Introduction}

Almost all physical activities incorporate elements of force, quickness, duration and range of motion. Exercises to overcome resistance are strength exercises; speed exercises maximize quickness and high frequency. Athletes vary in their talent to perform certain exercises. Talent is mostly genetic. Inherited speed, agility, vital capacity and Vo2 max play an important role in reaching high level of performance and are called dominant motor or bio-motor abilities. Motors refers to movement, the prefix bio-illustrates the biological importance of these abilities. In the field of games and sports also, there has been a great change with the help of scientific coaching and training. . Involvements in systematic training bring about desirable changes in physiological ability which enhances the athlete's performance in game like hockey. Modern field Hockey is a vigorous and speed endurance game which requires accelerating sprint, rough tackling, and power in hitting and speed endurance to sustain skillful play for seventy minutes. India women field Hockey is in infancy stage. It has to go long way to catch the world standard and in order to catch the world standard; there should be proper planning and implementation of the programme and the implemented programme should be evaluated from time to time so that the best result can be attained. To promote hockey players and identify promising talent at a young age, the pro-sport state government has established the first women hockey academy in Gwalior with active cooperation of Sport Authority of India (SAI) \& other state sports associations.

\section{Objective}

The purpose of this study was Assess the Physical and Physiological Effect of Program on Female Hockey Players. Also to find out the training effect in different phases of training.

\section{Materials and Method}

The study was carried out on the trainees who are enrolled under Madhya Pradesh state women hockey academy (M.P.S.W.H.A). Time series design was applied to find out the effect of training on physical and physiological variable as the progression of training goes on from preparatory to transitional phase.30 female hockey player enrolled under the scheme selected as a subject the age ranged from 16 to 21 years. The data were collected in different phase of training. The criterion measure for variable speed, agility, vital capacity and $\operatorname{Vo} 2$ max are as follows: 1.Speed was measured by 50 meters dash 2.Agility was measured by 10x4 meters shuttle run 3.Wet spirometer was used to measured vital capacity 4.To measure Vo2 Max cooper's 12 min run/walk test was administered. In order to compare the different phase data an one way analysis of variance (ANOVA) was applied with the help of L.S.D Post hoc test. The level of significance was set at 0.05 .

\section{Results}

The statistical analysis of data collected on thirty subjects belonging to different phase of training period (before and after) of one long term training plan of Madhya Pradesh State Women Hockey Academy. The data was examined by applying analysis of variance and the level of significance was set at 0.05 . After analysis of variance to find out the paired mean difference LSD post hoc test applied between the mean of different phases of training. To test the hypothesis, the level of significance was set at 0.05 . 


\section{International Journal of Science and Research (IJSR) \\ ISSN (Online): 2319-7064 \\ Index Copernicus Value (2013): 6.14 | Impact Factor (2015): 6.391}

Table 1: Analysis of variance of difference observation in relation to speed

\begin{tabular}{|c|c|c|c|c|}
\hline $\begin{array}{c}\text { Source of } \\
\text { variance }\end{array}$ & $\begin{array}{c}\text { Sum of } \\
\text { Squares }\end{array}$ & Df & $\begin{array}{c}\text { Mean } \\
\text { Square }\end{array}$ & F \\
\hline Between Groups & 1.767 & 6 & .294 & \multirow{2}{*}{$3.32 *$} \\
\cline { 1 - 4 } Within Groups & 17.984 & 203 & .089 & \\
\cline { 1 - 4 } Total & 19.751 & 209 & & \\
\hline
\end{tabular}

*significant, $\mathrm{F}_{0.05}(6,203)=2.14$

It is evident from Table- 1 that the calculated value of F-ratio (3.32) in relation to speed is higher than the tabulated Fvalue (2.14) at 0.05 level of significance. It shows that there is significant difference between mean of speed at different training phase from preparatory to transitional period. To find out the paired mean difference, the LSD Post Hoc test was used and revealed that there is significant difference between the paired mean of speed at different phase of training at pre-preparatory and post competition, pre preparatory and post transitional, $1^{\text {st }}$ intermediate of preparatory and post of competition, $1^{\text {st }}$ intermediate of preparatory and post transitional, $2^{\text {nd }}$ intermediate of preparatory and post of transitional, post of preparatory and post of competition, post of preparatory and post of transitional is $0.23,0.26,0.20,0.23,0.18,0.16$ and 0.19 respectively. The highest significant paired mean difference was recorded between the pre-preparatory and post of transitional (0.26) whereas the lowest significant paired mean difference was recorded between the post of preparatory and post of competition (0.16).

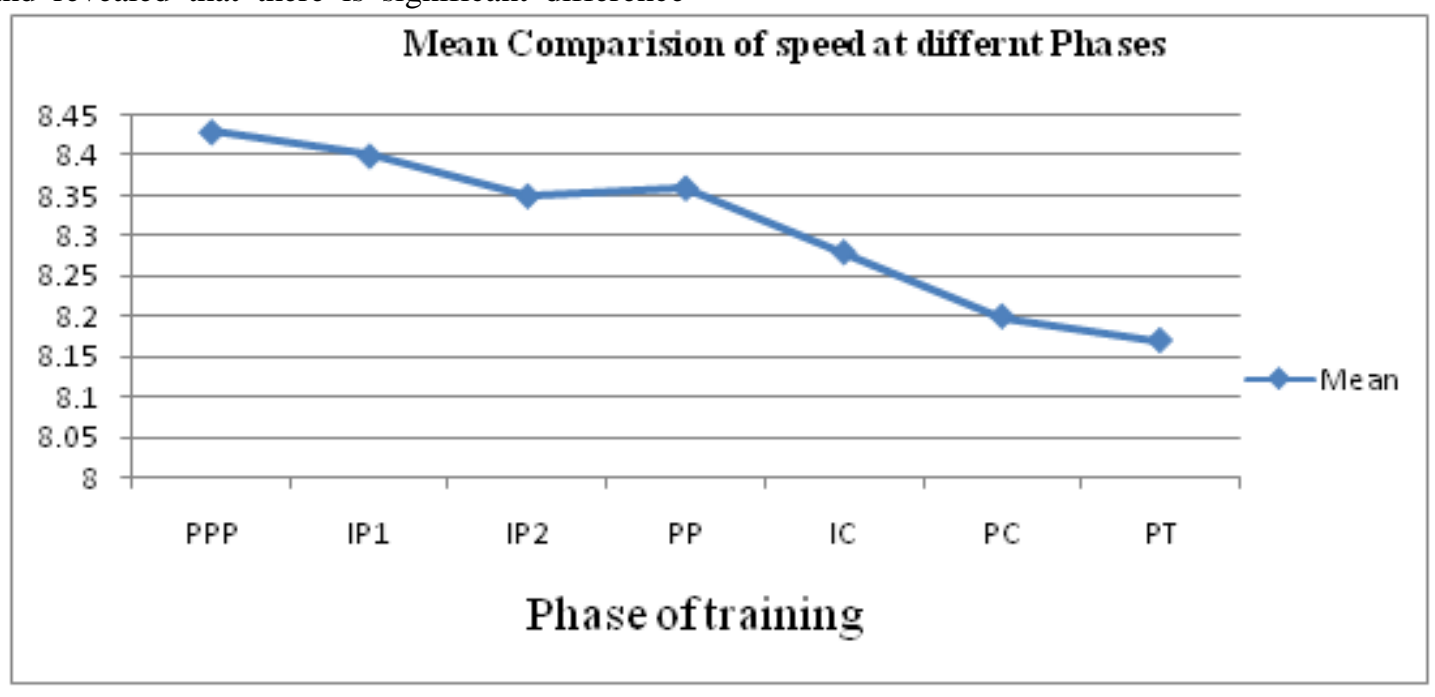

Table 2: Analysis of Variance of Difference Observation in Relation to Agility

\begin{tabular}{|c|c|c|c|c|}
\hline $\begin{array}{c}\text { Source of } \\
\text { variance }\end{array}$ & $\begin{array}{c}\text { Sum of } \\
\text { Squares }\end{array}$ & Df & $\begin{array}{c}\text { Mean } \\
\text { Square }\end{array}$ & F \\
\hline Between Groups & 2.480 & 6 & .413 & \\
\cline { 1 - 4 } Within Groups & 10.189 & 203 & .050 & \multirow{2}{*}{$8.23^{*}$} \\
\cline { 1 - 4 } Total & 12.668 & 209 & & \\
\hline
\end{tabular}

*significant, $\mathrm{F}_{0.05}(6,203)=2.14$

The above table evident that the calculated value of F-ratio (8.23) in relation to agility is much higher than the tabulated F-value (2.14) at 0.05 level of significance. It shows that there is significant difference between mean of agility at different training phase from preparatory to transitional period. To find out the paired mean difference, the LSD Post Hoc test was used and revealed that there is significant difference between the paired mean of agility at different phase of training at pre-preparatory and post of preparatory, pre preparatory and intermediate of competition, pre preparatory and post of competition, pre preparatory and post of transitional, $1^{\text {st }}$ intermediate of preparatory and post of preparatory, $1^{\text {st }}$ intermediate of preparatory and intermediate of competition, $1^{\text {st }}$ intermediate of preparatory and post of competition, $1^{\text {st }}$ intermediate of preparatory and post of transitional, $2^{\text {nd }}$ intermediate of preparatory and post of competition, $2^{\text {nd }}$ intermediate of preparatory and post of transitional, post of preparatory and post of transitional, intermediate of competition and post of transitional is 0.17 , $0.21,0.27,0.33,0.12,0.16,0.22,0.28,0.16,0.22,0.16$ and 0.12 respectively. The highest significant paired mean difference was recorded between the pre-preparatory and post of transitional (0.33) whereas the lowest significant paired mean difference was recorded between the first intermediate of preparatory and post of preparatory (0.12).Also between intermediate of competition and post of transitional phase(0.12). 
International Journal of Science and Research (IJSR)

ISSN (Online): 2319-7064

Index Copernicus Value (2013): 6.14 | Impact Factor (2015): 6.391

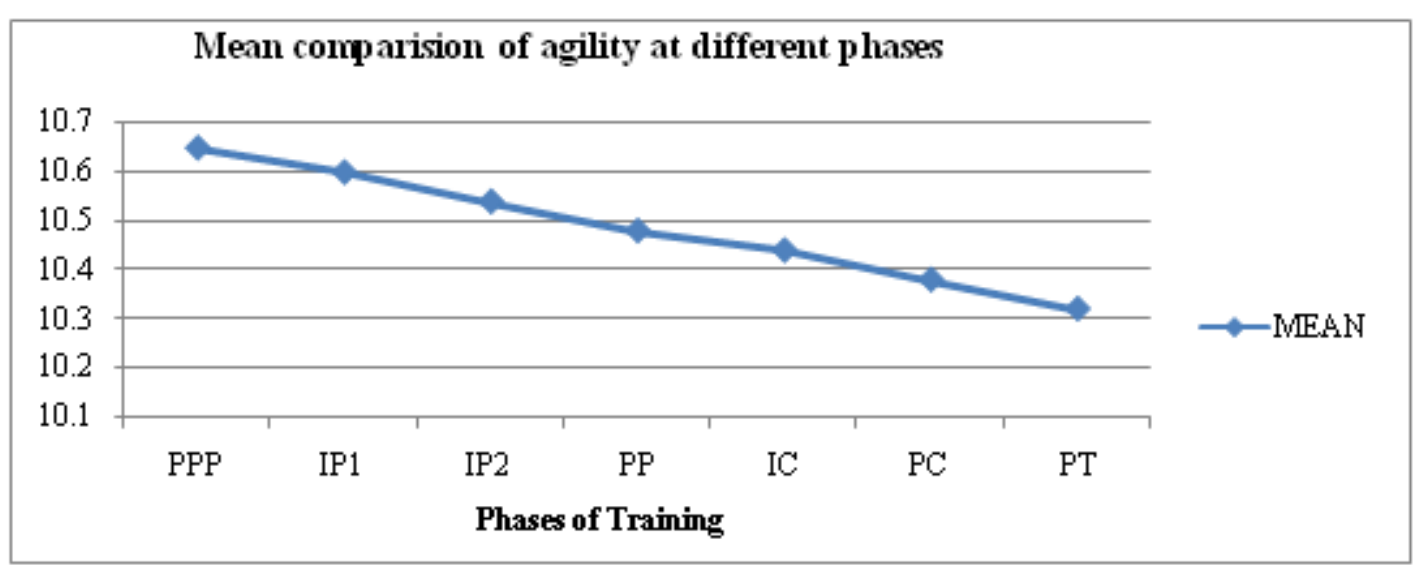

Table 3: analysis of varience of difference observation in relation to vital capacity

\begin{tabular}{|l|c|c|c|c|}
\hline $\begin{array}{c}\text { Source of } \\
\text { variance }\end{array}$ & $\begin{array}{c}\text { Sum of } \\
\text { Squares }\end{array}$ & Df & $\begin{array}{c}\text { Mean } \\
\text { Square }\end{array}$ & F \\
\hline Between Groups & 14.436 & 6 & 2.406 & \multirow{2}{*}{$27.09 *$} \\
\hline Within Groups & 18.028 & 203 & .089 & \\
\hline Total & 32.464 & 209 & & \\
\hline
\end{tabular}

*significant, $\mathrm{F}_{0.05}(6,203)=2.14$

It is evident from Table 3 that the calculated value of F-ratio (27.09) in relation to vital capacity is much higher than the tabulated F-value (2.14) at 0.05 level of significance. It shows that there is significant difference between mean of vital capacity at different training phase from preparatory to transitional period. To find out the paired mean difference, the LSD Post Hoc test was used and revealed that there is significant difference between the paired mean of vital capacity at different phase of training at pre-preparatory and $2^{\text {nd }}$ intermediate of preparatory, pre-preparatory and post preparatory, pre-preparatory and intermediate of competition, pre-preparatory and post of competition, prepreparatory and post of transitional, $1^{\text {ST }}$ intermediate preparatory and $2^{\text {nd }}$ intermediate of preparatory, $1^{\text {ST }}$ intermediate of preparatory and post $\mathrm{o}$ preparatory, $1^{\mathrm{ST}}$ intermediate preparatory and intermediate of competition, $1^{\text {ST }}$ intermediate preparatory and post of competition, $1^{\text {ST }}$ intermediate preparatory and post of transitional, $2^{\text {nd }}$ intermediate of preparatory and intermediate of competition, $2^{\text {nd }}$ intermediate of preparatory and post of competition, $2^{\text {nd }}$ intermediate of preparatory and post of transitional, post of preparatory and post of competition, post of preparatory and post of transitional, intermediate of competition and post of transitional is $0.37,0.47,0.60,0.66,0.77,0.24,0.34,0.47$, $0.53,0.64,0.23,0.29,0.40,0.19,0.30$ and 0.17 respectively. The highest significant paired mean difference was recorded between pre-preparatory and post of transitional (0.77) whereas the lowest significant paired mean difference was recorded between the intermediate of competition and post of transitional (0.17).

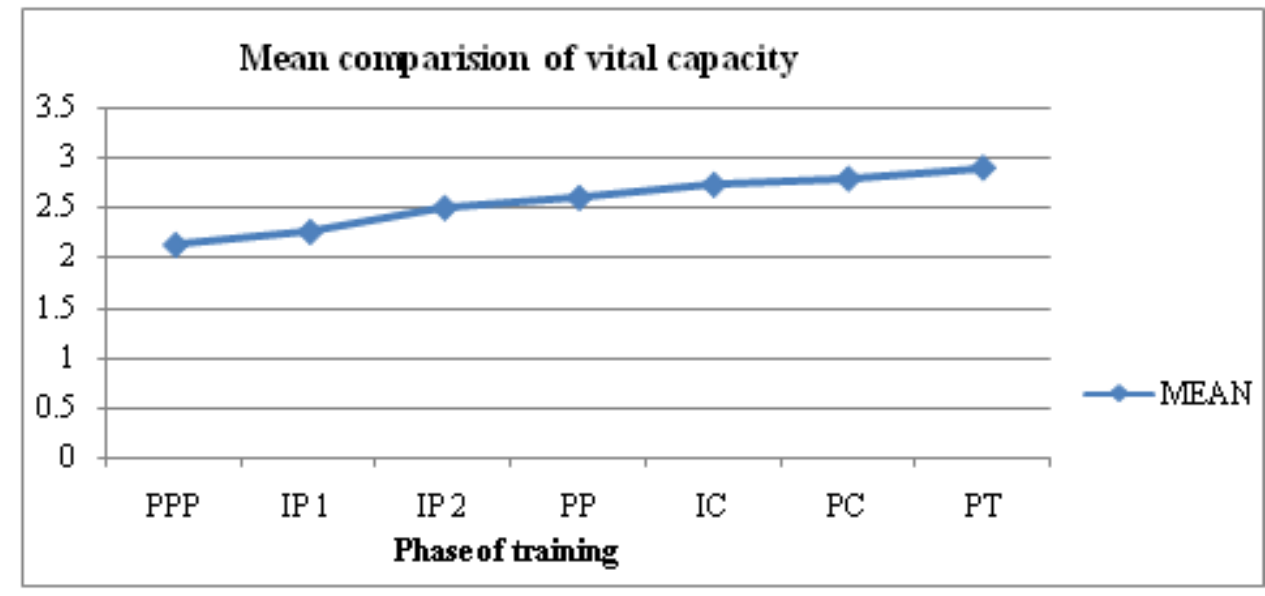

Table 4: Analysis of Varience of Difference Observation in Relation to $\mathrm{VO}_{2} \mathrm{Max}$

\begin{tabular}{|l|c|c|c|c|}
\hline \multicolumn{1}{|c|}{$\begin{array}{c}\text { Source of } \\
\text { variance }\end{array}$} & $\begin{array}{c}\text { Sum of } \\
\text { Squares }\end{array}$ & Df & $\begin{array}{c}\text { Mean } \\
\text { Square }\end{array}$ & \multirow{2}{*}{$F$} \\
\hline Between Groups & 491.947 & 6 & 81.991 & \multirow{2}{*}{$8.08^{*}$} \\
\cline { 1 - 4 } Within Groups & 2059.818 & 203 & 10.147 & \\
\hline Total & 2551.766 & 209 & & \\
\hline
\end{tabular}

*significant, $\mathrm{F}_{0.05}(6,203)=2.14$

It is evident from Table 4 that the calculated value of F-ratio (8.08) in relation to $\mathrm{VO}_{2} \max$ is much higher than the tabulated F-value (2.14) at 0.05 level of significance. It shows that there is significant difference between mean of vo2 max at different training phase from preparatory to transitional period. To find out the paired mean difference, the LSD Post Hoc test was used and revealed that there is significant difference between the paired mean of $\mathrm{VO}_{2}$ max at different phase of training at pre-preparatory and $2^{\text {nd }}$ intermediate of preparatory, pre-preparatory and post of preparatory, pre-preparatory and intermediate of competition, pre-preparatory and post of competition, prepreparatory and post of transitional, $1^{\text {ST }}$ intermediate of

\section{Volume 5 Issue 6, June 2016 www.ijsr.net}




\section{International Journal of Science and Research (IJSR) \\ ISSN (Online): 2319-7064 \\ Index Copernicus Value (2013): 6.14 | Impact Factor (2015): 6.391}

preparatory and post of preparatory, $1^{\mathrm{ST}}$ intermediate of preparatory and intermediate of competition, $1^{\mathrm{ST}}$ intermediate of preparatory and post of competition, $1^{\text {ST }}$ intermediate of preparatory and post of transitional, $2^{\text {nd }}$ intermediate of preparatory and post of competition is 2.69 , $3.63,3.70,4.48,4.25,2.28,2.36,3.13,2.91$ and 1.79 respectively. The highest significant paired mean difference was recorded between pre-preparatory and post of competition (4.48), on the other hand the lowest significant paired mean difference was recorded between $2^{\text {nd }}$ intermediate of preparatory and post of competition (1.79).

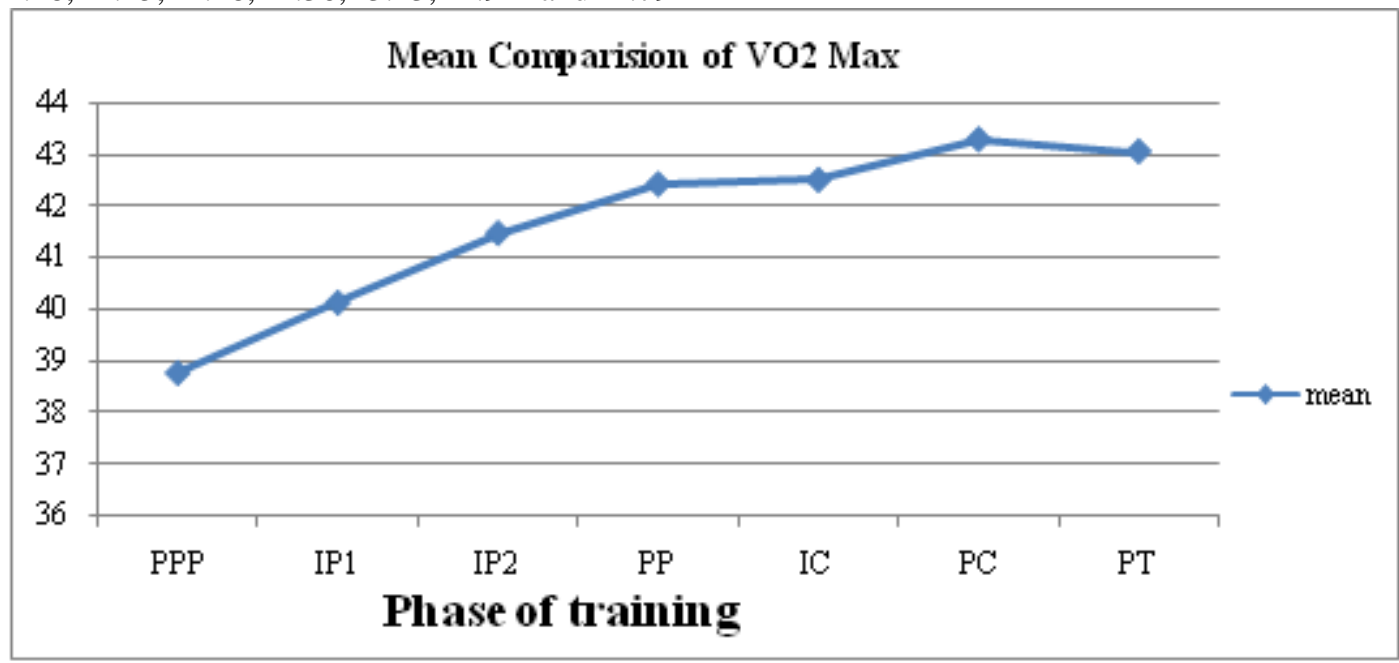

\section{Conclusion}

It has been firm view that the finding of the study sufficiently justified the objectives and vary purpose of the study on which study was conceptualized. The finding of the study clearly indicated that there was significant effect of training on speed from preparatory to transitional phase. Speed is an absolute quality which is basically understood and learnt as the potential factor and genetically based. As in case of agility the findings of agility showed that there was improvement of agility as the progression of training moved. Agility is relative factors based on speed, leg strength, flexibility \& coordination abilities which is finally controlled by finer neural control of the subject. The result of the study reveals that in case of physiological variable like vital capacity \& Vo2 max was statistically significant. Vital capacity findings indicate that there was positives improvement from preparatory to transitional phase. These significant changes in vital capacity may be attributed to the fact that the graded exercises resulted in higher capacity of lungs. The changes in training from preparatory to transitional phase of training were effective to improving Vo2 max. This may because of an increased oxygen delivery to the working muscles through an increased cardiac output and increased oxygen extraction from the blood by the skeletal muscles.

\section{References}

[1] Aziz A.R., "The relationship between maximal oxygen uptake and repeated sprint performance indices in field hockey and soccer players", Sport Medicine \& Fitness Division, 2000 Sep;40(3).

[2] Carey DG, Drake MM, Pliego GJ, Raymond RL., "Do hockey players need aerobic fitness? Relation between VO2max and fatigue during high-intensity intermittent ice skating", J Strength Cond Res. 21(3), 2007.

[3] Geithner CA, Lee AM, Bracko MR., "Physical and performance differences among forwards, defensemen, and goalies in elite women's ice hockey", J Strength Cond Res., 20(3), 2006.

[4] Miller TA, Thierry-Aguilera R, Congleton JJ, Amendola AA, Clark MJ, Crouse SF, Martin SM, Jenkins OC., "Seasonal changes in $\mathrm{VO}_{2} \max$ among Division $1 \mathrm{~A}$ collegiate women soccer players", J Strength Cond Res., 21(1), 2007. 